\title{
Modeling of dynamic loadings on a tower crane jib
}

\author{
Evgenij Kudryavtsev, Alexander Gavrilenko*, and Mostafa Jafari \\ Moscow State University of Civil Engineering, Yaroslavskoe shosse, 26, Moscow, 129337, Russia
}

\begin{abstract}
Article describe processes of modeling of dynamic loadings on on a tower crane jib and represent their in analytic and, graphic kinds with using of modern computer technologies. Complexity of such tasks is concluded in depending these characteristics from load characteristics of the crane, weights and inertial parameters of elements of the mechanism of the lifting of loads, having a nonlinear appearance. The proposed procedures of modeling allow to reduce time and costs of such calculations at least in several hundred times and effectively to carry out researches in any usage mode and on all design stages of tower cranes, providing good visual presentation of received results.
\end{abstract}

\section{Introduction}

Article describe process of modeling of dynamic loadings on a tower crane jib. It is necessary originally: to simulate the load characteristic of the tower crane in an analytical kind; to define the resulted moments of inertia of rotating bodies and lifted load to an engine rotor; to define time, a way and acceleration of dispersal of load at its lifting, depending on a load site on a jib and representation their in analytic and graphic kinds in MathCad system. [1][2]

The proposed procedures of modeling and calculations allow to reduce time and costs of such calculations at least in several hundred times and effectively to carry out researches in any usage mode and exploitation of transport means, providing good visual presentation of received results.[3]

\section{Statement of the problem}

The load characteristic of the tower crane in a graphic kind is known, as a rule, looks how is shown on fig. 1 .

\footnotetext{
${ }^{*}$ Corresponding author: sdm@mgsu.ru
} 


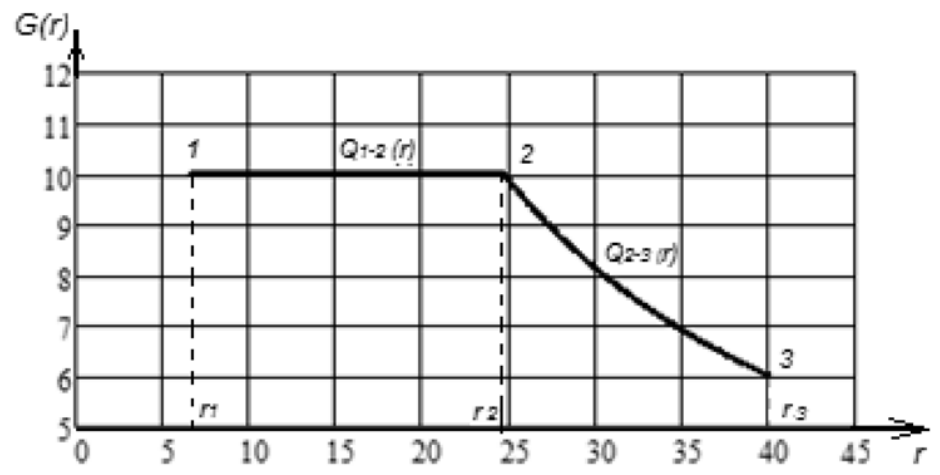

Fig. 1. An example of the load characteristic of the tower crane

In an analytical kind the load characteristic of the tower crane can be presented such expression.

- In the range $r_{1}-r_{2}$

- In the range $r_{2}-r_{3}$

$$
Q_{1-2}(r)=Q_{2},
$$

$$
Q_{2-3}(r)=\frac{M c r+M c l-M w c l-M w l-M i m-M c f l}{K s s c r \cdot((g+a a) \cdot(r-0,5 \cdot B+H 5 \cdot \sin (\alpha))} .
$$

where: $\quad M c r-$ moment from constructive weight of the crane in working status, $k N \cdot m$;

$\mathrm{Mcl}$ - moment from weight of counterload in working status $\mathrm{kN} \cdot \mathrm{m}$;

$M w c r$ - moment from wind loading on the crane in working order, $k N \cdot m$;

$M w l$ - moment from wind loading on load in working order, $k N \cdot m$;

Mimcr - inertia moment at crane dispersal, $k N \cdot m$;

Mimla - inertia moment at load dispersal along, $k N \cdot m$;

Mimlv - inertia moment at load dispersal on a vertical, $k N \cdot m$;

$M c f l$ - moment from centrifugal force of load, $k N \cdot m$;

Ksscr - factor of a stock of stability of the crane in working status;

$B$-base of the crane, $m$;

$\alpha$ - maximal gradient angle, degree;

$H 5$ - height of a heel of an arrow, $m$.

In an analytical kind can define the resulted moments of inertia of rotating bodies and lifted load to an engine rotor.

$$
\begin{aligned}
& \operatorname{Inp}(r)=\left(\delta \cdot(I r+0.5 \cdot I c)+\frac{0.5 \cdot I c+I 1}{\eta 1}+\frac{I 2}{i 1^{2} \cdot \eta 1 \cdot \eta 2}+\right. \\
& +\frac{I s c d}{i 1^{2} \cdot i 2^{2} \cdot \eta 1 \cdot \eta 2 \cdot \eta 3}+\frac{1000 \cdot(Q R(r) \cdot(1+K v l)+0.05 \cdot Q R(r)}{\eta 1 \cdot \eta 2 \cdot \eta 3 \cdot \eta p \cdot \eta b l^{n b l}} \cdot\left(\frac{V l l}{\omega n}\right)
\end{aligned}
$$

where: $\delta$ - factor influence of inertial weights of the mechanism of lifting of loads;

$\mathrm{Ir}$, Ic - inertia moments of engine rotor and coupler, $\mathrm{kgm}^{2}$;

I1, I2 - inertia moments of reducer shafts, $\mathrm{kgm}^{2}$;

Iscd - inertia moments of reducer shaft, coupler and drum, $\mathrm{kgm}^{2}$;

$Q R(r)$ - capacity of tower crane, tone

$\mathrm{KV} \mathrm{l}$ - factor of variability of loads;

$V I 1$ - speed of lifting of loads, $\mathrm{m} / \mathrm{s}$,

$\eta 1, \eta 2, \eta 3$ - reducer shafts efficiency; 
i1, i2 - transfer number of the stages of a reducer;

$\eta p, \eta b l$, - polispast and block efficiency;

$n b l$ - number of by-pass blocks.

\section{Modeling algorithm in system Mathcad}

This paragraph shows the program in the MATHCAD system in the form of screenshots of the computer screen.[4][5] This program can be used to calculate and simulate dynamic loads on the jib of a tower crane. In fig. 2,3 shows modelling of load characteristics of the tower crane process.

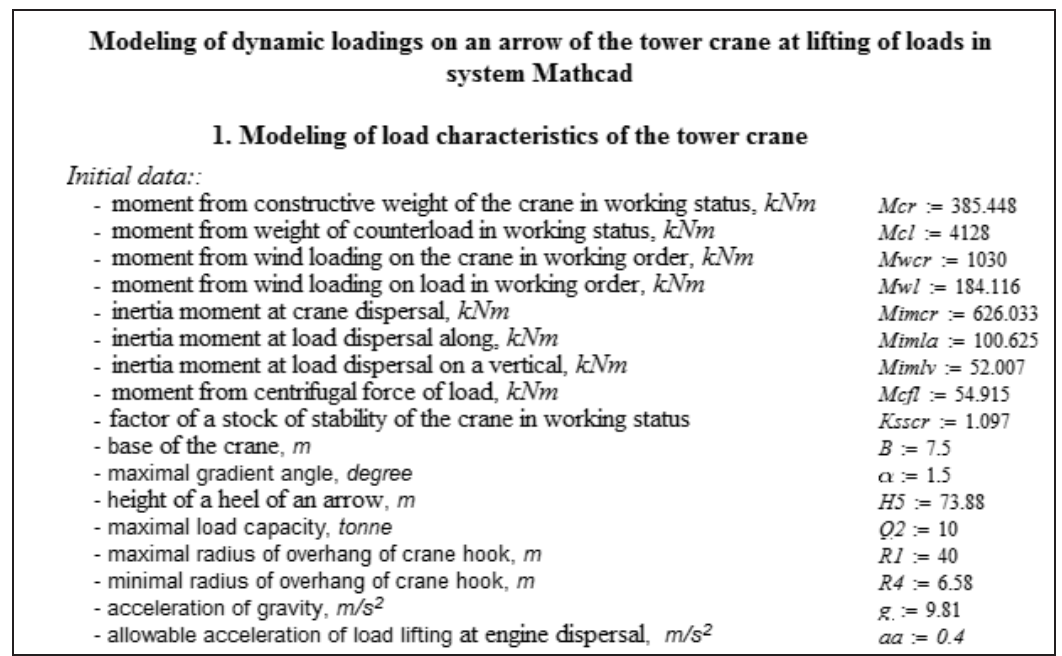

Fig. 2. The initial data for modeling of load characteristics.

Algorithm of calculation:

1. Total moments from inertial forces, $k N m$

$$
\text { Mim : }=\text { Mimcr }+ \text { Mimla }+ \text { Mimlv }
$$

2. Representation of the load characteristic of the tower crane in an analytical kind, tonne:

- in the range of 1 - 2

$$
Q 12(R):=Q 2
$$

- in the range of $2-3$

$$
Q 23(R):=\frac{M c r+M c l-M w c r-M w l-M i m-M c f l}{K s s c r \cdot[(g+a a) \cdot(R-0.5 \cdot B+H 5 \cdot \sin (\alpha \cdot \operatorname{deg}))]}
$$

3. Representation of the load characteristic of the tower crane in a graphic kind: - definition of co-ordinate of a point $\mathrm{r} 2$

$$
r l:=0.5 \cdot B+H 5 \cdot \sin (\alpha \cdot \operatorname{deg})
$$

$$
r 2:=\operatorname{root}[(Q 23(R)-Q 2), R, r 1, R I]
$$

$$
r l=5.684
$$

- definition of the load characteristic of the crane in the form of two lines

$$
Q R(r):=\mid \begin{array}{ll}
Q 23(r) & \text { if } r 2 \leq r \leq R 1 \\
Q 12(r) & \text { if } R 4 \leq r \leq r 2
\end{array}
$$

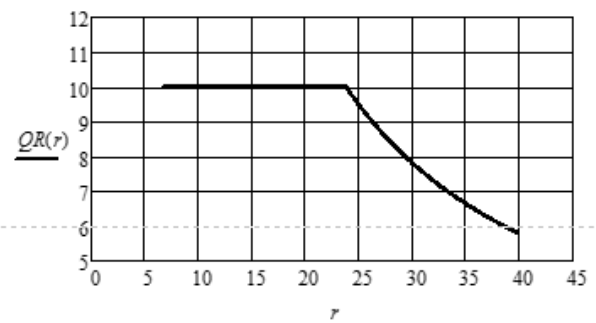

Fig. 3. Algorithm of calculation load characteristics. 
The second paragraph of the program shows calculation the acceleration of lifting loads. In the figures 4-8 initial data and calculation algorithm are shown.

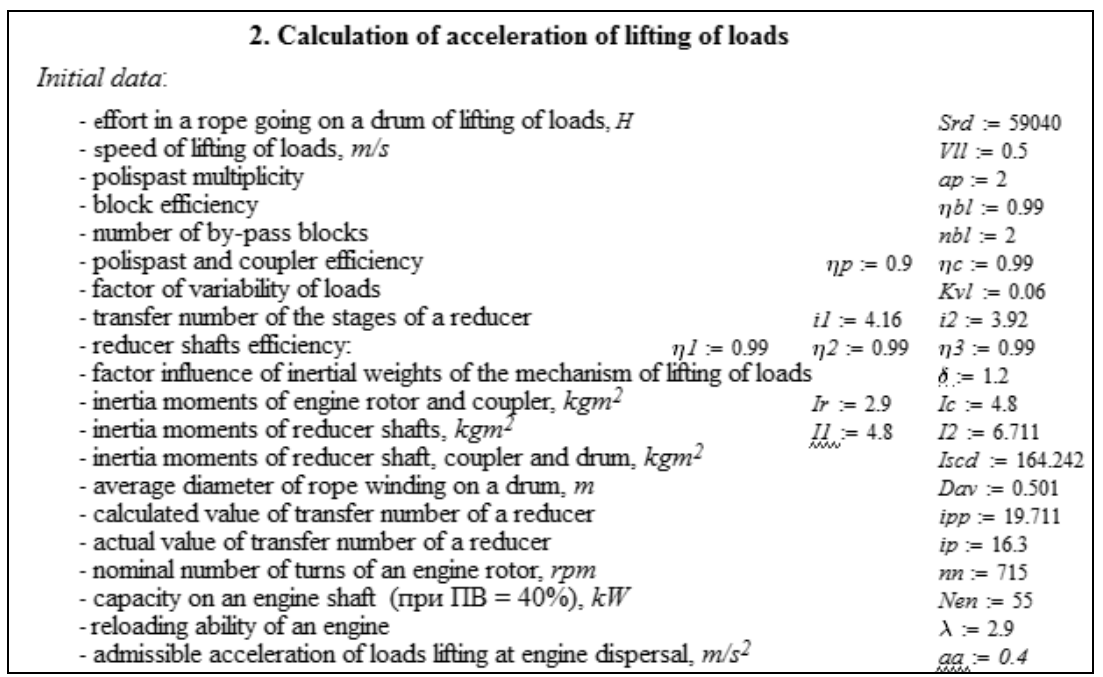

Fig. 4. Calculation of acceleration of lifting loads. Initial data.

Calculation algorithm

1. Nominal angular speed of rotation of an engine rotor, $\mathrm{rad} / \mathrm{s}$

$$
\omega n:=\frac{2 \cdot \pi \cdot n n}{60}
$$

2. Nominal moment of an engine rotor, $\mathrm{Nm}$

$$
M n:=\frac{1000 \cdot N e n}{\omega n}
$$

3. Critical moment of an engine rotor, $\mathrm{Nm}$

$$
M k:=M n \cdot \lambda
$$$$
M k=2.13 \times 10^{3}
$$

4. Reduced moment of inertia of rotating bodies and lifted load to an engine shaft, $\mathrm{kgm}^{2}$

$$
\begin{aligned}
\operatorname{In} p(r):= & {[\delta \cdot(I r+0.5 \cdot I c)]+\frac{0.5 \cdot I c+I 1}{\eta 1}+\frac{I 2}{i I^{2} \cdot \eta l \cdot \eta 2}+\frac{I s c d}{i 1^{2} \cdot i 2^{2} \cdot \eta I \cdot \eta 2 \cdot \eta 3} } \\
& +\frac{1000 \cdot[Q R(r) \cdot(1+K v l)+0.05 \cdot Q R(r)]}{\eta l \cdot \eta 2 \cdot \eta 3 \cdot \eta p \cdot \eta b l^{n b l}} \cdot\left(\frac{V l l}{\omega n}\right)^{2}
\end{aligned}
$$

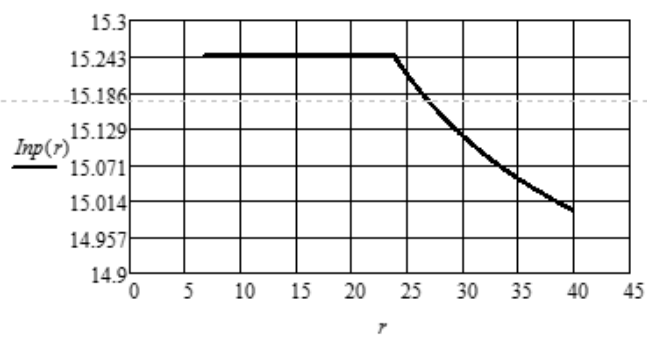

Fig. 5. Calculation of acceleration of lifting loads. Points 1-4. 
5. Moment of static resistance, $\mathrm{Nm}$

$$
M s r:=\frac{S r d \cdot D a v}{2 \cdot i 1 \cdot i 2 \cdot \eta 1 \cdot \eta 2 \cdot \eta 3 \cdot \eta p \cdot \eta b l^{n b l}}
$$$$
M s r=1.06 \times 10^{3}
$$

6. Average starting moment, $\mathrm{Nm}$

$$
\text { Mas }:=\frac{M k+1.1 \cdot M n}{2}
$$$$
\text { Mas }=1.469 \times 10^{3}
$$

7. Time of dispersal of lifted load, $s$

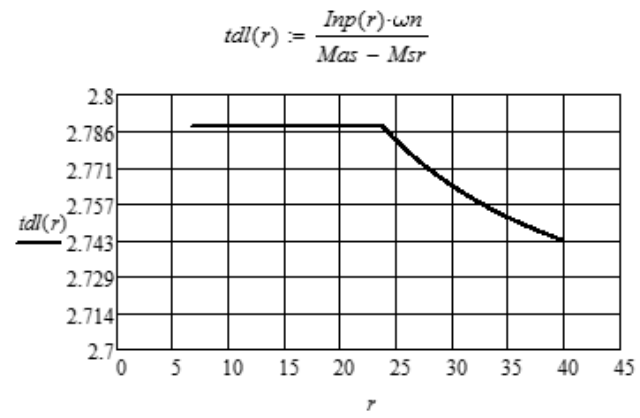

Fig. 6. Calculation of acceleration of lifting loads. Points 5-7.

8. Actual speed $(\mathrm{m} / \mathrm{s})$ and acceleration of dispersal $\left(\mathrm{m} / \mathrm{s}^{2}\right)$ of lifing of loads,

$$
V a:=V l l \cdot \frac{i p p}{i p} \quad \operatorname{adl}(r):=\frac{V a}{t d l(r)} \quad V a=0.605
$$

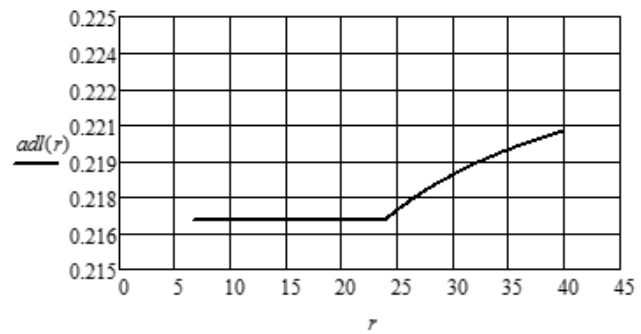

9. Way (height) of dispersal of lifted load, $m$

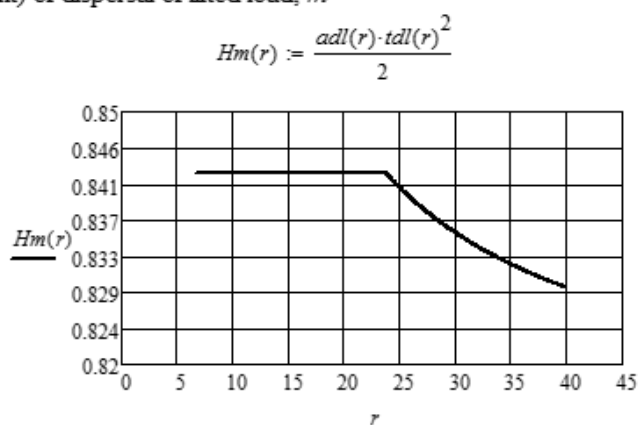

Fig. 7. Calculation of acceleration of lifting loads. Points 8,9. 
10. Dynamic loadings on a crane arrow at loads lifting depending on a location of load, $k N$

$$
F(r):=\mid \begin{array}{ll}
Q 23(r) \cdot \operatorname{adl}(r) & \text { if } r 2 \leq r \leq R 1 \\
Q 12(r) \cdot \operatorname{adl}(r) & \text { if } R 4 \leq r \leq r 2
\end{array}
$$

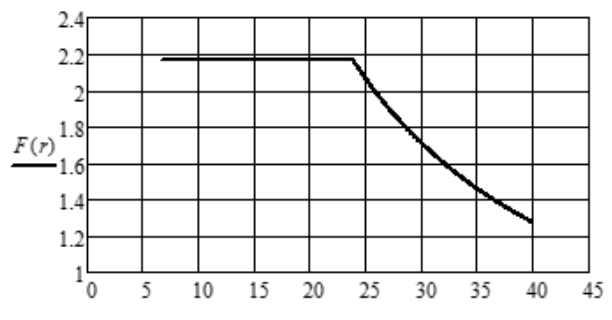

Fig. 8. Calculation of acceleration of lifting loads. Point 10.

\section{Conclusion}

The proposed procedures of modeling of dynamic loadings on a tower crane jib allow to reduce time and costs of such calculations at least in several hundred times and effectively to carry out researches in any usage mode and all design stages of tower cranes, providing good visual presentation of received results.

The reported study was funded by RFBR according to the research project № 20-38-90168

\section{References}

1. Vahlamov V. K. Structures, calculation and operational properties of cars. - M: Academy. 2007. - 560 p.

2. Krajcinovic D 1995 Continuum Damage Mechanics: when and how? Int. J. Damage Mechanics 4 pp 217-229

3. Y Kudryavtsev and A Gavrilenko 2019 IOP Conf. Ser.: Mater. Sci. Eng. 698022081.

4. Y Kudryavtsev and A Gavrilenko 2020 IOP Conf. Ser.: Mater. Sci. Eng. 753042076.

5. E. Kudryavtsev, A. Gavrilenko 9/2020 Construction and road building machinery journal., pp 40-43. 